\title{
A REVISÃO DO \\ CÓDIGO FLORESTAL BRASILEIRO
}

\author{
GERD SPAROVEK \\ ALBERTO BARRETTO \\ ISRAEL KLUG \\ LEONARDO PAPP \\ JANE LINO
}

\section{RESUMO}

O artigo reúne informações e análises que pretendem demonstrar a importância do Código Florestal para a conservação das importantes reservas de áreas preservadas que ainda temos no Brasil, bem como a necessidade e os caminhos para sua revisão, visando alcançar o possível e plausível equilíbrio entre o respeito à natureza e o desenvolvimento agrícola.

PALAVRAS-CHAVE: Código florestal; modelagem espacialmente explícita; desenvolvimento agrícola; conservação.

\section{ABSTRACT}

The article offers information and analysis that intend to demonstrate the importance of the Brazilian Forest Act for the protection of the remaining preserved natural vegetation in Brazil, as well as the reasons and guidelines for its revision, in order to reach the possible and desired balance between respect to the natural environment and improved agricultural development.

KEYWORDS: Brazilian Forest Act; spatially explicit modeling; agricultural development; conservation.

\section{CÓDIGO FLORESTAL E DIREITO AMBIENTAL}

Embora alegislação ambiental seja um tema de grande destaque na atualidade - como comprovam as discussões em torno das propostas de alteração do Código Florestal [CF](Lei 4.771/65) -, a existência de normas jurídicas disciplinando a utilização de recursos naturais não é novidade no Direito. No Brasil colonial, existiam regras jurídicas que restringiam a utilização de recursos naturais, prevendo severas sanções em caso de descumprimento. Constava das Ordenações Filipinas a seguinte determinação: 
[...] primeiramente hei por bem e mando, que nenhuma pessoa possa cortar, nem mandar cortaro dita Pau-Brasil, porsi, ou seus escravos ou feitoresseus, semexpressa licença ou escrito do Provedor-Mor [...] e o que contrário fizer, incorrerá em pena de morte e confiscação de toda a sua fazenda.

Esses comandos legais não estavam direcionados à preservação e à manutenção da flora nativa; ao contrário, tinham por objetivo garantir o monopólio da Coroa portuguesa na exploração da madeira extraída ${ }^{1}$. Nesse momento histórico, à luz da legislação, os recursos ambientais representavam apenas objetos a serem utilizados nos processos produtivos e, portanto, deveriam ser apropriados individualmente, por meio de operações garantidas pelo direito. Isto se justifica pela concepção da relação ser humano/meio ambiente da época, baseada na ideia da inesgotabilidade dos recursos naturais e na crença de que a domesticação da natureza "[...] é uma tarefa possível, fácil e sem efeitos indiretos negativos" 2 .

Com o tempo, essa concepção da relação ser humano/ambiente foi questionada, e está atualmente superada em todos os campos do conhecimento. Especificamente no Direito brasileiro, a reestruturação da relação ser humano/meio ambiente tem na Constituição Federal de 1988 (CRFB/88) um de seus marcos mais importantes, justamente por se tratar da principal norma do ordenamento jurídico nacional. De maneira inovadora, a CRFB/88 dedicou um capítulo específico para a questão ambiental, reconhecendo expressamente que "todos têm direito ao meio ambiente ecologicamente equilibrado, bem de uso comum do povo e essencial à sadia qualidade de vida, impondo-se ao Poder Público e à coletividade o dever de defendê-lo e preservá-lo para as presentes e futuras gerações" (art.225).

Assim, à luz do direito, a tutela do meio ambiente não se restringe ao valor dos recursos naturais para os processos produtivos. A própria Constituição reconheceu que o equilíbrio ambiental é um elemento indispensável para a qualidade de vida sadia. Ela também ampliou os próprios beneficiários da defesa e da preservação ambiental, posto que incluiu expressamente as próximas gerações. Entre as diversas inovações introduzidas pelo art. 225, destacam-se as noções de "enfoque multidimensional" da influência do meio ambiente na (qualidade de) vida dos seres humanos e de "equidade integeracional". Essa nova concepção jurídica da relação ser humano/ambiente situa as discussões relativas ao direito ambiental num patamar consideravelmente mais amplo, permitindo promover significativos avanços na busca de mecanismos jurídicos eficazes na tutela do meio ambiente.

A constatação de que o meio ambiente assume papel de destaque na CRFB/88 não deve levar ao tratamento da legislação ambiental de modo isolado, ou seja, sem considerar os demais direitos fundamen-
[1] Cf. Carvalho, Carlos Gomes de. Introdução ao direito ambiental. 3. ed. São Paulo: Letras e Letras, 2001, p. 28.

[2] Soares, Cláudia Alexandra Dias. O imposto ecológico: contributo para o estudo dos instrumentos econômicos de defesa do ambiente. Coimbra: Coimbra Editora, 2001, p. 34 . 
[3] Grau, Eros Roberto. Ensaio e discurso sobre a interpretação/aplicação do direito. São Paulo: Malheiros, p. 189-90.

[4] Canotilho,JoséJoaquim Gomes. Direito constitucional. Coimbra:Almedina, 1992, p. 234.

[5] Ibidem, p. 1099.

[6] Derani, Cristiane. Direito ambiental econômico. 2 ed. São Paulo: Max Limonad, 2001, p. 87. tais também reconhecidos no âmbito dessa Constituição. Segundo Eros Roberto Grau, "não se interpreta a Constituição em tiras, aos pedaços [pois] uma norma jurídica isolada, destacada, desprendida do sistema jurídico não expressa significado normativo algum"3. $\mathrm{O}$ estudo sistemático da CRFB $/ 88$ permite identificar parâmetros que norteiam as interpretações constitucionais viáveis, ou seja, que buscam conciliar a proteção ambiental com os demais direitos fundamentais, visando a "[...] coordenação e combinação dos bens jurídicos em conflito ou em concorrência de forma a evitar o sacrifício (total) de uns em relação aos outros" 4 . A Constituição de 1988 elegeu expressamente objetivos fundamentais para o Brasil, os quais norteiam toda e qualquer atividade de interpretação do texto constitucional e estão plasmados nos valores inscritos nos arts. $1^{\circ}$ e $3^{\circ}$, tais como soberania, dignidade da pessoa humana, valores sociais do trabalho e da livre iniciativa, garantia de desenvolvimento nacional, erradicação da pobreza e redução das desigualdades sociais e regionais. Esses formam princípiosestruturantesfundamentais, assim entendidos por indicarem " [...] as ideias diretivas básicas de toda a ordem constitucional" 5 e, portanto, também aplicáveis à tutela jurídica do meio ambiente.

A produção da legislação que disciplina a atividade do ser humano em relação aos recursos naturais também deve considerar, portanto, as suas consequências para a promoção de um ambiente socialmente justo e economicamente viável. Como afirma Cristiane Derani:

[...] aquilo que está disposto como direito ambiental pode estar também enquadrado no conteúdo do direito econômico, [pois] tanto a Constituição não pode ser interpretada aos pedaços, como politicas econômicas e ambientais não são livros diferentes de uma biblioteca, manuseados, cada uma a sua vez, segundo o interesse e conveniência de algum leitor 6 .

Ao mesmo tempo em que a CRFB/88 ampliou significativamente a tutela do meio ambiente, também inseriu as atividades de produção da legislação num contexto de grande complexidade, pois busca a difícil conciliação de valores que, não raramente, são contrários.

As discussões relativas às propostas de alteração (ou manutenção) das normas atualmente vigentes no Código Florestal seguem o mesmo roteiro, ou seja, não se pode desconsiderar sua repercussão no mundo dos fatos, em seus diversos aspectos (ecológico, social, econômico etc.), considerando que

[...] o texto é abstrato e geral (isto é, sem referência a motivos e contexto real). Mas o aspecto da realidade referida pela norma constitui conjuntamente seu sentido (essesentido não pode, apartirdaí,serperseguido apartado da realidade a serregulamentada).A realidade étanto parte da norma quanto o texto [...]?. 
Embora a redação original do CF remonte ao ano de 1965, especialmente nos últimos anos vários dispositivos foram inseridos diretamente na mencionada Lei por meio de medidas provisórias, sucessivamente reeditadas e atualmente vigendo como MP 2.166-67. Em decorrência de tais medidas, por exemplo, foi conferido novo regime jurídico às denominadas Reservas Legais, ampliando os percentuais das áreas nas propriedades que devem ser mantidas com cobertura florestal/vegetal a tal título (art. 16). Durante os últimos anos também foram produzidos diversos atos normativos destinados a complementar os institutos previstos no Código através de resoluções editadas pelo Conselho Nacional do Meio Ambiente (Conama), que definem, por exemplo, como identificar as áreas de preservação permanente em topos de morro ou em restingas (Resolução Conama 303/o2).

A análise das repercussões concretas da aplicação dos dispositivos gerais e abstratos da norma jurídica não pode ser realizada exclusivamente a partir do direito, pois este não dispõe, isoladamente, de suficiente ferramental teórico e técnico.É necessário uma abordagem interdisciplinar, na forma de "uma prática essencialmente 'política', ou seja, como uma negociação entre diferentes pontos de vista, para enfim decidir sobre a representação considerada adequada tendo em

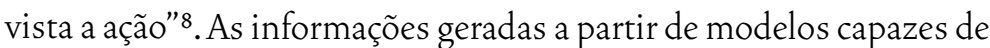
estimar o alcance e as consequências da aplicação do Substitutivo assumem importância nas discussões relativas às propostas de alteração do Código Florestal.

\section{TERRAS BRASILEIRAS, USO E SITUAÇÃo FUNDIÁRIA}

A Tabela 1 apresenta informações sobre os usos da terra no Brasil agrupadas em classes que representam a agropecuária (lavouras e pastagens) e a Vegetação Natural (VN)9. A agropecuária ocupa 275 $\mathrm{Mha}^{10}$ ( $32 \%$ do Brasil), sendo a maior parte utilizada com pastagens (211 Mha). Os números médios agregados para o Brasil escondem importantes variações. Na região Sul a agropecuária ocupa $69 \%$ e no Bioma Mata-Atlântica, $72 \%$. O mesmo ocorre com a VN que representa 63\% do território brasileiro, mas varia de 33\% na região Sul até $80 \%$ na região Norte, de apenas $28 \%$ na Mata-Atlântica até $77 \%$ na Amazônia,e 56\% do Cerrado.A situação de Unidades de Conservação ou Terras Indígenas (UC/TI) ${ }^{11}$ é ainda mais assimétrica, indo da quase inexistência nas regiões Sul, Sudeste e Nordeste, até 38\% na região Norte. Nas regiões onde a ocupação das terras é mais consolidada (Sul, Sudeste, Centro Oeste, Nordeste) a proporção de UC/TI em relação ao total de vegetação natural é muito pequena, ou seja, a maior parte desse tipo de vegetação está em terras privadas.
[8] Fourez, Gérard. A construção das ciências: introdução à filosofia e à ética das ciências. Trad. Luiz Paulo Rouanet. São Paulo: Editora da Unesp, 1995 , pp. 136-7.

[9] "Vegetação natural" são áreas que preservam boa parte de sua cobertura vegetal natural, seja ela floresta, caatinga, pampa ou outra fisionomia. Estas áreas podem ter utilização produtiva como pastagens, extrativismo, podem estar em processo de regeneração ou ocupadas com atividades agrícolas pouco intensivas nas quais não houve a remoção completa da cobertura vegetal original em grandes extensões. Elas possuem elevado valor ecológico porque preservam a biodiversidade da flora, e são ambientes favoráveis para a preservação da fauna e outras formas de vida. São importantes também no contexto de diversos serviços ambientais como a preservação dos recursos hídricos, do ciclo hidrológico, e ajudam na assimilação do $\mathrm{CO}_{2}$ emitido pelos combustíveis fósseis, entre outros.

[10] $\mathrm{M}=$ milhões $\left(10^{6}\right) ;$ ha $=$ hectare $\left(10.000 \mathrm{~m}^{2}\right) ; 100 \mathrm{ha}=1 \mathrm{~km}^{2}$.

[11] UC/TI = Unidade de Conservação de Proteção Integral ou Terra Indígena. 


\begin{tabular}{|c|c|c|c|c|c|c|c|c|c|c|}
\hline \multirow{3}{*}{ Recorte } & \multirow{2}{*}{\multicolumn{2}{|c|}{$\begin{array}{c}\text { Área } \\
\text { Processada }\end{array}$}} & \multicolumn{4}{|c|}{ Agropecuária } & \multirow{2}{*}{\multicolumn{2}{|c|}{$\begin{array}{c}\text { Vegetação } \\
\text { Natural }\end{array}$}} & \multirow{2}{*}{\multicolumn{2}{|c|}{ uc/TI }} \\
\hline & & & \multicolumn{2}{|c|}{ Total } & \multirow{2}{*}{$\begin{array}{l}\text { Agric. } \\
\text { Mha }\end{array}$} & \multirow{2}{*}{$\begin{array}{l}\text { Pasto } \\
\text { Mha }\end{array}$} & & & & \\
\hline & Mha & Pr. BR & Mha & Pr. Rec. & & & Mha & Pr. Rec. & Mha & Pr. Rec. \\
\hline Brasil & 849 & 1,00 & 275 & 0,32 & 57 & 211 & 537 & 0,63 & 175 & 0,21 \\
\hline
\end{tabular}

\begin{tabular}{|c|c|c|c|c|c|c|c|c|c|c|}
\hline \multicolumn{11}{|l|}{ Região } \\
\hline Norte & 385 & 0,45 & 47 & 0,12 & 1 & 46 & 309 & 0,80 & 147 & 0,38 \\
\hline Nordeste & 155 & 0,18 & 55 & 0,35 & 4 & 50 & 91 & 0,58 & 6 & 0,04 \\
\hline Centro-Oeste & 161 & 0,19 & 74 & 0,46 & 20 & 54 & 74 & 0,46 & 18 & 0,11 \\
\hline Sudeste & 92 & 0,11 & 59 & 0,64 & 18 & 38 & 33 & 0,36 & 3 & 0,03 \\
\hline Sul & 58 & 0,07 & 40 & 0,69 & 15 & 23 & 19 & 0,33 & 1 & 0,02 \\
\hline
\end{tabular}

Bioma

\begin{tabular}{|c|c|c|c|c|c|c|c|c|c|c|}
\hline Amazônia & 420 & 0,49 & 66 & 0,16 & 5 & 61 & 322 & 0,77 & 155 & 0,37 \\
\hline Caatinga & 83 & 0,10 & 28 & 0,34 & $<1$ & 28 & 48 & 0,59 & 1,1 & 0,01 \\
\hline Cerrado & 204 & 0,24 & 88 & 0,43 & 22 & 64 & 114 & 0,56 & 14 & 0,07 \\
\hline Mata Atlântica & 112 & 0,13 & 80 & 0,72 & 27 & 50 & 31 & 0,28 & 3 & 0,03 \\
\hline Pampas & 18 & 0,02 & 10 & 0,57 & 3 & 6 & 7 & 0,42 & 0,2 & 0,01 \\
\hline Pantanal & 15 & 0,02 & 2 & 0,13 & $<1$ & 2 & 13 & $\circ, 87$ & 1,0 & 0,07 \\
\hline
\end{tabular}

Onde: $\operatorname{Pr} . \mathrm{BR}=$ proporção do Brasil; Pr. Rec. = proporção do recorte; Agric. = agricultura, principalmente lavouras; UC/TI = Unidade de Conservação de proteção integral ou Terra Indígena; $\mathrm{Mha}=$ milhões de hectares.

$\mathrm{Na}$ Amazônia, que ainda apresenta um estoque de Terras Públicas não Destinadas (TPñD) muito grande e enorme insegurança jurídica sobre a posse das terras, a situação não é muito diferente. A quantidade de vegetação natural em unidades de conservação ou terras indígenas consolidadas representa 152 Mha, apenas $47 \%$ da VN existente. Os outros 53\% de VN da Amazônia, que correspondem a 170 Mha, encontram-se predominantemente em TPñD, dos quais cerca de 100 Mha ocorrem em áreas contínuas e bem preservadas, com elevado potencial, portanto, para criação de UC/TI destinadas à proteção integral. A regularização fundiária desta enorme região, ainda preservada em sua maioria, com a consequente destinação de suas terras ainda conservadas para fins de preservação, representa, assim, uma das mais importantes medidas para a conservação das florestas brasileiras. Enquanto permanecerem sem demarcação, sem dono, sem destino e quase sem legislação específica que as proteja, com exceção da Lei de Crimes Ambientais, o isolamento e a sorte serão as únicas aliadas destas florestas. 


\begin{tabular}{|c|c|c|c|c|c|c|c|}
\hline \multirow{3}{*}{ Recorte } & \multicolumn{2}{|c|}{ APP } & \multicolumn{2}{|c|}{ RL } & \multirow{2}{*}{$\begin{array}{c}\text { Pasto } \\
\text { Disp. Ag. }\end{array}$} & \multirow{2}{*}{$\begin{array}{l}\text { VN ñ } \\
\text { prot. }\end{array}$} & \multirow{2}{*}{$\begin{array}{c}\text { VN ñ } \\
\text { prot. Alta } \\
\text { Ap. }\end{array}$} \\
\hline & ex. & déf. & ex. & déf. & & & \\
\hline & \multicolumn{7}{|c|}{ Mha } \\
\hline
\end{tabular}

\begin{tabular}{|c|c|c|c|c|c|c|c|}
\hline \multicolumn{8}{|c|}{ CF Atual } \\
\hline Brasil & $100^{*}$ & 43 & 236 & 42 & 61 & 103 & 7,0 \\
\hline \multicolumn{8}{|l|}{ Região } \\
\hline Norte & 28 & 7 & 123 & 14 & 12 & 20 & 0,2 \\
\hline Nordeste & 29 & 13 & 33 & 7 & 7 & 43 & 1,2 \\
\hline Centro-Oeste & 16 & 7 & 50 & 12 & 24 & 20 & 3,2 \\
\hline Sudeste & 16 & 10 & 18 & 5 & 12 & 12 & 1,4 \\
\hline Sul & 11 & 7 & 12 & 4 & 6 & 7 & 1,0 \\
\hline
\end{tabular}

\section{Bioma}

\begin{tabular}{|c|c|c|c|c|c|c|c|}
\hline Amazônia & 31 & 9 & 146 & 25 & 15 & 15 & 0,0 \\
\hline Caatinga & 16 & 7 & 15 & 1 & 4 & 25 & 0,5 \\
\hline Cerrado & 25 & 9 & 47 & 6 & 29 & 43 & 3,8 \\
\hline Mata Atlântica & 22 & 16 & 22 & 9 & 11 & 10 & 1,0 \\
\hline Pampas & 4 & 2 & 3 & 1 & 3 & 3 & 0,8 \\
\hline Pantanal & 2 & 0,2 & 3 & 0,02 & 1 & 7 & 0,8 \\
\hline
\end{tabular}

\begin{tabular}{l|c|c|c|c|c|c|c}
\hline \multicolumn{7}{c}{ Cenário: Isenção de 4 Módulos Fiscais do cálculo de RL } \\
\hline Brasil & 100 & 43 & $\mathbf{2 0 6}$ & $\mathbf{1 5}$ & $\mathbf{6 8}$ & 103 & 7,0 \\
\hline
\end{tabular}

\section{Região}

\begin{tabular}{|c|c|c|c|c|c|c|c|}
\hline Norte & 28 & 7 & 111 & 4 & 15 & 20 & 0,2 \\
\hline Nordeste & 29 & 13 & 28 & 2 & 7 & 43 & 1,2 \\
\hline Centro-Oeste & 16 & 7 & 44 & 6 & 27 & 20 & 3,2 \\
\hline Sudeste & 16 & 10 & 15 & 2 & 12 & 12 & 1,4 \\
\hline Sul & 11 & 7 & 9 & $\mathbf{1}$ & 6 & 7 & 1,0 \\
\hline
\end{tabular}

\begin{tabular}{l|c|c|c|c|c|c|c}
\hline \multicolumn{1}{c}{ Cenário: Compensação de RL no Bioma } \\
\hline Brasil & 100 & 43 & 236 & $\mathbf{1 3}$ & $\mathbf{7 2}$ & $\mathbf{7 1}$ & $\mathbf{1 1 , 7}$ \\
\hline
\end{tabular}

\begin{tabular}{|c|c|c|c|c|c|c|c|}
\hline \multicolumn{8}{|l|}{ Bioma } \\
\hline Amazônia & 31 & 9 & 146 & 13 & 23 & o & 0,0 \\
\hline Caatinga & 16 & 7 & 15 & o & 4 & 23 & 0,6 \\
\hline Cerrado & 25 & 9 & 47 & o & 30 & 37 & 7,4 \\
\hline Mata Atlântica & 22 & 16 & 22 & o & 12 & 1 & 1,2 \\
\hline Pampas & 4 & 2 & 3 & 0 & 3 & 2 & 1,4 \\
\hline Pantanal & 2 & 0,2 & 3 & 0 & 1 & 7 & $\mathbf{1}, \mathbf{I}$ \\
\hline
\end{tabular}




\begin{tabular}{|c|c|c|c|c|c|c|c|}
\hline \multirow{3}{*}{ Recorte } & \multicolumn{2}{|c|}{ APP } & \multicolumn{2}{|c|}{ RL } & \multirow{2}{*}{$\begin{array}{c}\text { Pasto } \\
\text { Disp. Ag. }\end{array}$} & \multirow{2}{*}{$\begin{array}{l}\text { VN ñ } \\
\text { prot. }\end{array}$} & \multirow{2}{*}{$\begin{array}{c}\text { VN ñ } \\
\text { prot. Alta } \\
\text { Ap. }\end{array}$} \\
\hline & ex. & déf. & ex. & déf. & & & \\
\hline & \multicolumn{7}{|c|}{ Mha } \\
\hline \multicolumn{8}{|c|}{ Cenário: Compensação de RL em APP } \\
\hline Brasil & 100 & 43 & 236 & 35 & 63 & 103 & 7,0 \\
\hline \multicolumn{8}{|l|}{ Bioma } \\
\hline Amazônia & $3 I$ & 9 & 146 & 21 & 16 & 15 & 0,0 \\
\hline Caatinga & 16 & 7 & 15 & 1 & 4 & 25 & 0,5 \\
\hline Cerrado & 25 & 9 & 47 & 4 & 29 & 43 & 3,8 \\
\hline Mata Atlântica & 22 & 16 & 22 & 8 & 11 & 10 & 1,0 \\
\hline Pampas & 4 & 2 & 3 & 1 & 3 & 3 & 0,8 \\
\hline Pantanal & 2 & o & 3 & o & 1 & 7 & 0,8 \\
\hline \multicolumn{8}{|c|}{ Cenário: Compensação de RL em APP e Bioma + Isenção de 4 MF + Anistia de recuperação de APP } \\
\hline Brasil & 100 & o & 206 & o & 72 & 88 & 12,3 \\
\hline \multicolumn{8}{|l|}{ Bioma } \\
\hline Amazônia & 31 & 0 & 127 & 0 & 23 & 6 & 0,0 \\
\hline Caatinga & 16 & o & 14 & 0 & 4 & 24 & 0,6 \\
\hline Cerrado & 25 & o & 44 & o & 30 & 40 & 7,4 \\
\hline Mata Atlântica & 22 & 0 & 16 & 0 & 12 & 7 & 1,9 \\
\hline Pampas & 4 & 0 & 3 & 0 & 3 & 3 & 1,4 \\
\hline Pantanal & 2 & o & 3 & 0 & 1 & 7 & 1,1 \\
\hline
\end{tabular}

Onde: $\mathrm{APP}=$ Área de Preservação Permanente; $\mathrm{RL}=$ Reserva Legal; ex = exigida; déf. = déficit; Pasto Disp. Ag. = Área de pastagem de aptidão elevada e média para produção agrícola disponível após alocação de RL; VN ñ prot. = Vegetação Natural não protegida pelo código florestal após alocação de RL; VN ñ prot. Alta Ap. = Vegetação Natural não protegida pelo código florestal após alocação de RL em terras de alta aptidão agrícola; CF = Código Florestal; $\mathrm{M}$ ha = milhões de hectares, $\mathrm{MF}=$ Módulo Fiscal.

* Os números apresentados em fonte regular representam os valores estimados pela aplicação do Código Florestal atual; nos cenários os números em itálico não diferem daqueles registrados no CF atual, e os em negrito diferem.

Nas áreas de agropecuária consolidada em que não há unidades de conservação ou terras indígenas, a vegetação natural remanescente está, evidentemente, localizada em terras de uso privado. Excluindo o Bioma Amazônia, no qual a regularização fundiária precede qualquer aspecto no contexto de sua conservação, o Código Florestal é, portanto, o principal instrumento legal que incide sobre a proteção e a restauração da vegetação natural, por ele regular sua proteção em terras privadas. No Cerrado $87 \%$ da VN existente ocorre em áreas privadas, na Mata-Atlântica, $92 \%$, nos Pampas, 99\%, e na Caatinga, $98 \%$. 
Esta realidade mais do que justifica a manutenção do Código Florestal como instrumento essencial ao equilíbrio entre o interesse privado da produção agrícola e o interesse coletivo da preservação ambiental e seu aprimoramento.

\section{FUNCIONAMENTO DO CÓDIGO FLORESTAL}

O Código Florestal aplica-se às propriedades privadas. Nele é definido que todas as glebas agrícolas precisam manter áreas de preservação permanente (APP) e reservas legais (RL). As APP são de interesse prioritário para preservação dos recursos hídricos e suas áreas de recarga. Elas incluem uma faixa de terras ao longo das margens dos rios, nascentes, lagos e reservatórios de águas, as áreas muito íngremes, topos de morro e altitudes elevadas. Trata-se de áreas de preservação exclusiva, não podendo ser utilizadas para atividades agropecuárias, extração florestal ou uso recreativo. Sua definição é independente do tamanho da propriedade é igual em todo Brasil.

As reservas legais não fazem parte das áreas de preservação permanente; devem ser mantidas com vegetação natural nas fazendas com o propósito geral de preservação da flora (diversidade e valor ecológico na paisagem). O tamanho das reservas legais é variável e definido como uma porcentagem das glebas rurais, variando de no máximo $80 \%$ nas florestas situadas na Amazônia Legal, até $20 \%$ nas áreas fora da Amazônia Legal. Elas permitem algum uso de baixo impacto, mas sem remoção completa da cobertura vegetal natural. As restrições de uso impedem que estas áreas sejam utilizadas para atividades agrícolas mecanizadas como o cultivo de soja, milho, cana e a pecuária com base em pastagens plantadas.

No Código Florestal atual, as propriedades rurais que não estejam em conformidade com os requisitos de APP e RL têm como principal opção restaurar estas áreas, ou seja, reverte o uso a elas destinado para sua condição florística natural por meio do plantio ou indução da regeneração. Alguns mecanismos de redução de exigência e compensação de não conformidade de reserva legal estão previstos no Código, mas, devido a restrições decorrentes de sua definição e regulamentação, estes não são aplicados de forma abrangente.

\section{RAZÕES PARA A REVISÃo dO CÓDIGO FLORESTAL ATUAL}

\section{Desenvolvimento do setor agropecuário}

As supostas restrições impostas pela legislação ambiental ao desenvolvimento do setor agropecuário são utilizadas com frequência como justificativa para a necessidade de revisão do Código Florestal e dos critérios para a criação de unidades de conservação ou terras in- 
[12] Cf. Miranda, Evaristo Eduardo de e outros. "O alcance da legislação ambiental e territorial". Agroanalysis, vol. $12, \mathrm{n}^{\circ} 28,2008$, pp. 1-6.

[13] Sistemas intensivos de produção comercial de gado de corte podem ser rentáveis em até 10 cabeças por ha. $\mathrm{Na}$ maior parte das regiões pecuárias do Brasil, a divisão das pastagens e seu manejo rotacionado permitem alcançar esta lotação, sem a necessidade de investimentos em correção do solo ou adubação.

[14] Algumas regiões pecuárias do Brasil têm restrições para o aumento da lotação, como o Pantanal ou a região do Sertão Nordestino. Mesmo considerando estas condições, as lotações maiores que podem ser alcançadas na pecuária das regiões Sul, Sudeste e nos Cerrados podem facilmente compensar as limitações impostas às regiões de baixa aptidão pecuária, levando os valores médios a 1,5 cabeças por hectare. dígenas e reservas quilombolas ${ }^{12}$. Outra forma de analisar a questão, porém,éverificar a possibilidade de as áreas já desmatadas e utilizadas para uso agropecuário poderem, se utilizadas eficientemente em sua totalidade, atender ao desenvolvimento do setor.

A análise conjunta da Tabela 1 e 2 permite algumas reflexões. As pastagens representam 3,5 vezes a soma de todas as outras formas de produção agrícola. Dados do último Censo Agropecuário (2006) indicam um rebanho bovino de aproximadamente 180 milhões de cabeças ocupando $158 \mathrm{Mha}$, o que resulta numa lotação média de 1,14 cabeças por ha. O desfrute atual, ou seja, a porcentagem do rebanho abatido por ano,éde $22 \%$, gerando um abate de 40 milhões de cabeças por ano para atender o mercado doméstico $(80 \%)$ e as exportações.

Evitando comparações com outras regiões como Estados Unidose Europa devidoà natureza distinta das bases da produção, consideramos uma projeção a partir do que pode ser feito no Brasil com a tecnologia disponível. A lotação de 1,14 cabeças por hectare indica um uso muito extensivo da terra. Mantendo a pecuária não integrada com a agricultura e pensando apenas na adoção de poucos recursos tecnológicos ${ }^{13}$, a lotação média poderia facilmente atingir 1,5 cabeças por hectare ${ }^{14}, \mathrm{e}$ o desfrute do rebanho, 30\%. Se considerarmos alternativas tecnológicas mais intensivas, como a correção do solo, adubação na formação das pastagens, uso das forrageiras melhoradas, manejo reprodutivo e sanitário eficientes, estes índices poderiam ser ainda maiores. Com esses números, o mesmo abate de 40 milhões de cabeças ocuparia uma área de apenas 89 Mha, ou seja, 69 Mha de pastagens deixariam de ser necessários para alcançar a mesma produção. O efeito vem da combinação de um número maior de animais por área e de um abate de maior porcentagem do rebanho. Como resultado, além de uma redução importante nas emissões de gases do efeito estufa, e da menor degradação associada à produção, também teríamos uma carne de maior qualidade sendo ofertada ao consumidor. Nesse cenário, o crescimento do setor agropecuário estaria contribuindo para o desenvolvimento do país. A eventual redução de sua áreas em 69 Mhaé maior do que a soma da área de todos os outros usos agrícolas do Brasil.

Das terras atualmente ocupadas com pasto, 61 Mha apresentam elevada e média aptidão para lavouras. São terras de pouca declividade, com fertilidade boa ou razoável, situadas em regiões em que é possível produzir sem irrigação; terras que já estão desmatadas, mas em grande parte utilizadas com pouca eficiência, e que poderiam servir para a expansão das lavouras. Um terço disto está no Cerrado, a principal região de expansão da fronteira agrícola.

$\mathrm{Na}$ teoria é simples: a pecuária de corte torna-se mais produtiva (não muito, não são necessários índices muito elevados) liberando um enormeestoque de terras férteis, suficiente para dobrar a área atual 
de nossas lavouras. Melhor para todos, passamos a ter uma pecuária moderna, eficiente, que no final das contas vai colocar no mercado um produto de melhor qualidade e com uma pegada ecológica muito menor no que diz respeito a desmatamento ou emissão de gases de efeito estufa. Esta mudança abre um enorme espaço para a expansão da área de soja e milho, atendendo crescentes demandas por exportação, e da agroenergia baseada na cana. E, o mais importante, sem derrubar uma árvore sequer! Toda a mudança ocorreria em áreas já desmatadas, atualmente em uso agropecuário.

Este exercício teórico demonstra caminhos viáveis - por não dependerem de nenhum conhecimento ou coisa não existente no dia a dia denossa agropecuária - para uma enormeexpansão da agropecuária nacional apenas pelo bom uso das áreas já convertidas. A teoria, no entanto,é separada da prática por diversas razões que fazem com quea conversão das florestas em pastagens pouco produtivas ainda seja um negócio rentável e atraente no Brasil, porém nenhuma delas ligada à real necessidade de terras para a produção agropecuária. As alegações de que a legislação ambiental impõe restrições não contornáveis para o desenvolvimento do setor agropecuário são equivocadas, mas extremamente úteis para justificar e permitir a manutenção da ineficiência de alguns setores, e acobertar as reais razões que levam a continuada expansão de nossa fronteira agrícola.

\section{A não conformidade}

Tanto no caso das áreas de preservação permanente como no caso das reservas legais, a situação de irregularidade ou não conformidade com o Código Florestal é muito expressiva. Não considerando os topos de morro, que somam aproximadamente 39 Mha no Brasilis e uma subestimativa das APP ao longo das margens dos rios (ripárias, ou matas ciliares) decorrentes da metodologia básica utilizada nesta análise ${ }^{16}$, numa área total de APP de 100 Mha o déficité de 43 Mha. Nas áreas de reservas legais o quadro é igualmente desanimador. Dos 235 Mha de RL necessários para cumprir o Código, mesmo considerando a hipótese otimista de todos os fazendeiros destinarem os remanescentes que ainda existem em suas propriedades para esta finalidade e utilizarem os mecanismos de compensação local para arrematar o que lhes falta nas próprias terras, ainda faltariam 42 Mha de vegetação natural para atender as exigências do Código Florestal.A Figura 1 apresenta a distribuição deste déficit. Ele ocorre em todas as regiões em que a atividade agropecuária é intensiva, cobrindo igualmente das primeiras terras colonizadas ao atual arco de desmatamento e Mapito-BA ${ }^{17}$.

A não conformidade ocorre por diversas razões, incluindo as constantes mudanças nas exigências da legislação, a definição imprecisa de alguns mecanismos, a falta de fiscalização e a não aceitação das restri-
[15] Cf. Victoria, Daniel de Castro, Hott, Marcos Cicarini e Miranda, Evarsito Eduardo. "Delimitação de áreas de preservação permanente em topos de morro para o território brasileiro". Revista Geográfica Acadêmica, vol. 2, $\mathrm{n}^{\circ} 2,2008$, pp. 66-72.

[16] Cf. Sparovek, Gerd e outros. "Brazilian agriculture and environmental legislation: status and future challenges". Environmental Science $\&$ Technology, vol. 44, 2010, pp. 6046-53.

[17] Mapito-BA é uma denominação dada às áreas de chapada dos estados do MA, PI, TO e BA de elevada aptidão agrícola e que ainda se encontram cobertas por cerrado.Junto com a região do arco de desmatamento nas bordas da floresta Amazônica, é a região de maior conversão de vegetação natural em uso agrícola na atualidade. 


\section{FIGURA}

Déficit mínimo de Áreas de Preservação Permanente, com exceção de topo-de-morro, e Reserva Legal na aplicação do Código Florestal atual
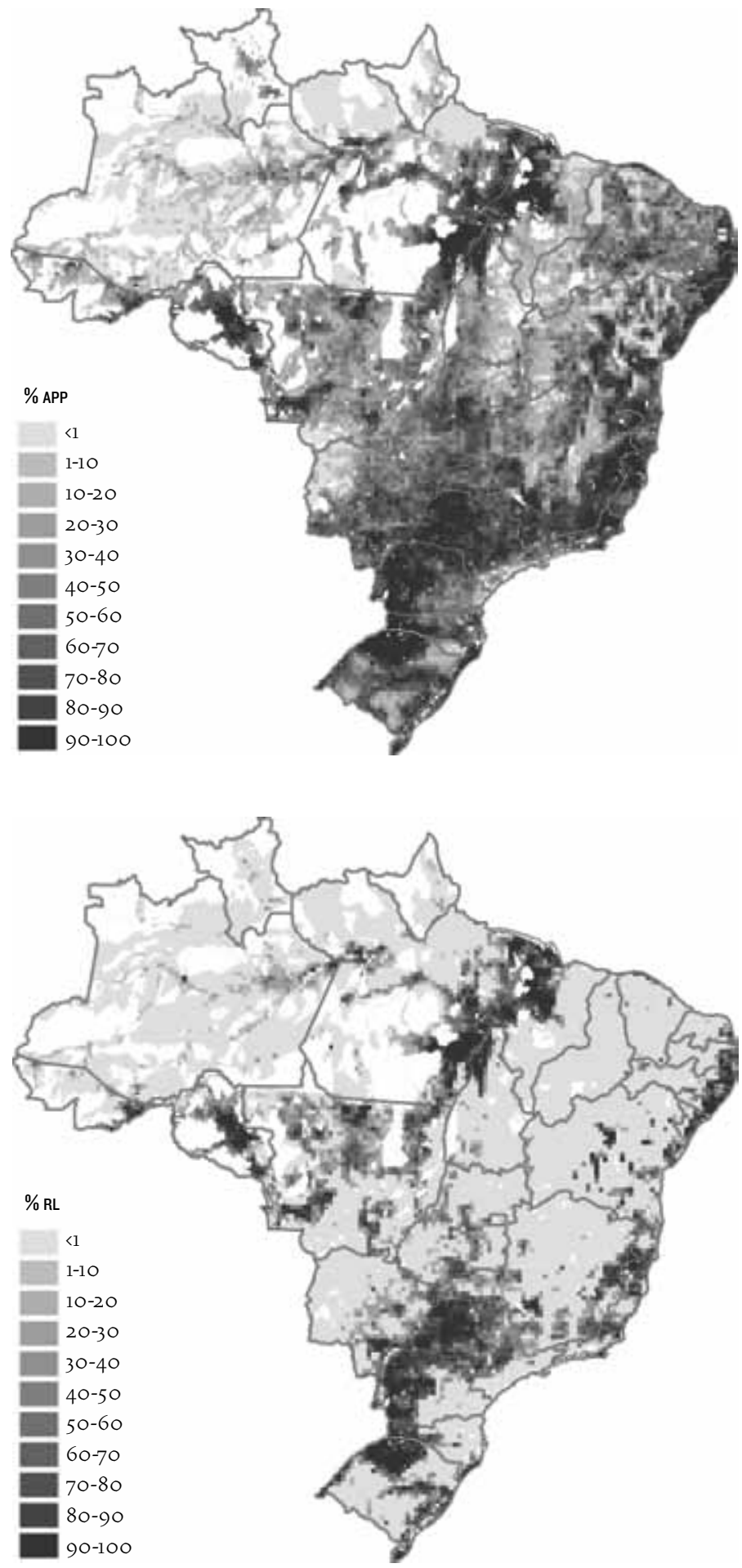

Obs.: O quadriculado (pixels) dos mapas corresponde ao grid de $25 \times 25 \mathrm{Km}$ utilizado na modelagem para o cálculo das informações representadas. 
ções pelos produtores rurais. O passivo acumulado ao longo dos anos é com certeza grande o suficiente para gerar dúvidas sobre a capacidade econômica da restauração da vegetação natural, os custos envolvidos e os possíveis benefícios implicados (econômicos e ecológicos). A conversão de 85 Mha de terras atualmente em uso produtivo em florestas pode gerar impactos socioeconômicos enormes e o desmatamento de novas áreas. Provavelmente, não haveria capacidade técnica ou logística implantada para executar a restauração nesta imensidão de terras, considerando os prazos curtos.

Uma das alternativas possíveis é utilizar o mecanismo da restauração preferencialmente nas áreas de maior relevância ecológica, como, por exemplo, as APP ou regiões indicadas por estudos ecológicos e econômicos, e aplicar mecanismos de compensação como alternativas à restauração. O Substitutivo aponta para esta direção.

\section{Vazamento}

Além dos déficits em áreas de preservação permanente e de reserva legal, o Código Florestal também tem alguns pontos cegos. Mesmo com a sua aplicação na íntegra sobrariam ainda 103 Mha sem proteção, terras privadas com vegetação natural que poderiam ser legalmente desmatadas (Tabela 2, Figura 2). Mesmo considerando que há pouca precisão nesta estimativa para a Amazônia, por não estar claro ainda o que é terra pública, privada, devoluta, posse ou grilada na região, os números são impressionantes, mesmo em regiões de agricultura consolidada: no Nordeste, representam $43 \mathrm{Mha}$ ( $47 \%$ de sua VN); no Centro-Oeste, 20 Mha (24\% de sua VN); no Cerrado, 43 Mha (37\% de sua VN); na Mata-Atlântica, $10 \mathrm{Mha}(32 \%$ de sua VN). Estas áreas representam terras com vegetação natural fora de APP localizadas em situações em que há mais VN do que aquela necessária para atender às exigências de reserva legal e compensação local, ou seja, regiões em que a vegetação natural ainda é abundante e ocupa a maior parte da paisagem.

A necessidade de crescimento em área da agropecuária não justifica a revisão do Código Florestal, bem como de outros mecanismos de preservação da vegetação natural, considerando aspectos técnicos ou práticos da capacidade produtiva do setor. Em algumas regiões, a falta de opções de desenvolvimento, a ausência de remuneração pela VN que excede a exigência legal, a frouxa fiscalização, a valorização imobiliária de terras desmatadas, a existência de mercado para produtos de desmatamento (carvão vegetal, madeira) e aspectos culturais da utilização da terra como reserva patrimonial são, provavelmente, as razões de fundo que justificam a contínua expansão da fronteira agrícola no Brasil por meio do desmatamento.Aocupação com pecuária extensiva destas terras é consequência, e não a causa do desmatamento. A utilização dos argumentos produtivistas visa criar uma agenda aceitável, 
simpática ou favorável, procurando atenuar (ou ocultar) as razões de fundo, injustificáveis do ponto de vista do interesse coletivo.

Qualquer ação de desenvolvimento do setor agropecuário equilibrado com a conservação da vegetação natural terá como ponto fundamental a intensificação da pecuária de corte em prazo curto nos 61 Mha de pastagens de média ou elevada aptidão agrícola em que isto é possível. Essa intensificação depende mais da construção de uma nova visão empresarial e cultural por parte de produtores, frigoríficos e consumidores e de políticas de acesso a recursos e assistência técnica do que de pesquisa e desenvolvimento (P\&D) ou inovações tecnológicas. A utilização adequada e produtiva das áreas já ocupadas com agropecuária garante, do ponto de vista nacional, uma enorme capacidade de desenvolvimento saudável do setor por muitas décadas.

O cumprimento integral do Código Florestal exigiria a necessidade de restauração de enormes passivos (pelo menos 85 Mha de áreas produtivas revertidas para $\mathrm{VN}$ ), ao mesmo tempo em que permitiria o desmatamento adicional de extensas áreas ainda preservadas (vazamento). Essa dinâmica de uso da terra, além de não ser realista, considerando a viabilidadeeconômica,técnicaeosimpactos sociais, levariaaconsequências ambíguas do ponto de vista da conservação.As áreas restauradas poderiam resultar em valor ecológico muito inferior àquele das áreas ainda preservadas. O plantio das espécies arbóreas nativas não recupera imediatamente toda biodiversidade existente anteriormente; isto, se vier a acontecer, pode levar muito tempo. Portanto, além de pouco provável, este cenário não garante que objetivos ecológicos sejam alcançados.

Observando a distribuição geográfica dos passivos, onde a agropecuária se consolidou, ocorreu bastante desmatamento, muito além daquilo que a lei e o interesse pela conservação permitem. Mas felizmente, ainda há, no Brasil, enormes extensões de terras preservadas, e que não precisam ser desmatadas. Pelo menos não com a justificativa da necessidade de desenvolver nossa agropecuária.Aceitaro argumento de que "oudesenvolvemosou preservamos" é uma armadilha na qual não devemos cair. Os poucos beneficiados de eventualmente acreditarmos nisto certamente não irão nos retribuir a confiança.

\section{AS NOVIDADES DO SUBSTITUTIVO E SUAS CONSEQUÊNCIAS}

\section{A nova lógica formada com novas ênfases}

O Substitutivo não criou muitos mecanismos novos, mas combinou os velhos ingredientes de forma completamente diferente. Muito mais do que uma discussão a respeito do efeito isolado de uma ou outra mudança, ou de quem se beneficia com elas quando vistas de maneira isolada - entre pequenas e grandes mudanças contamos 45 alterações - vale analisar primeiro a nova lógica do conjunto. 


\section{FIGURA 2}

Distribuição da vegetação natural não protegida pelo Código Florestal atual

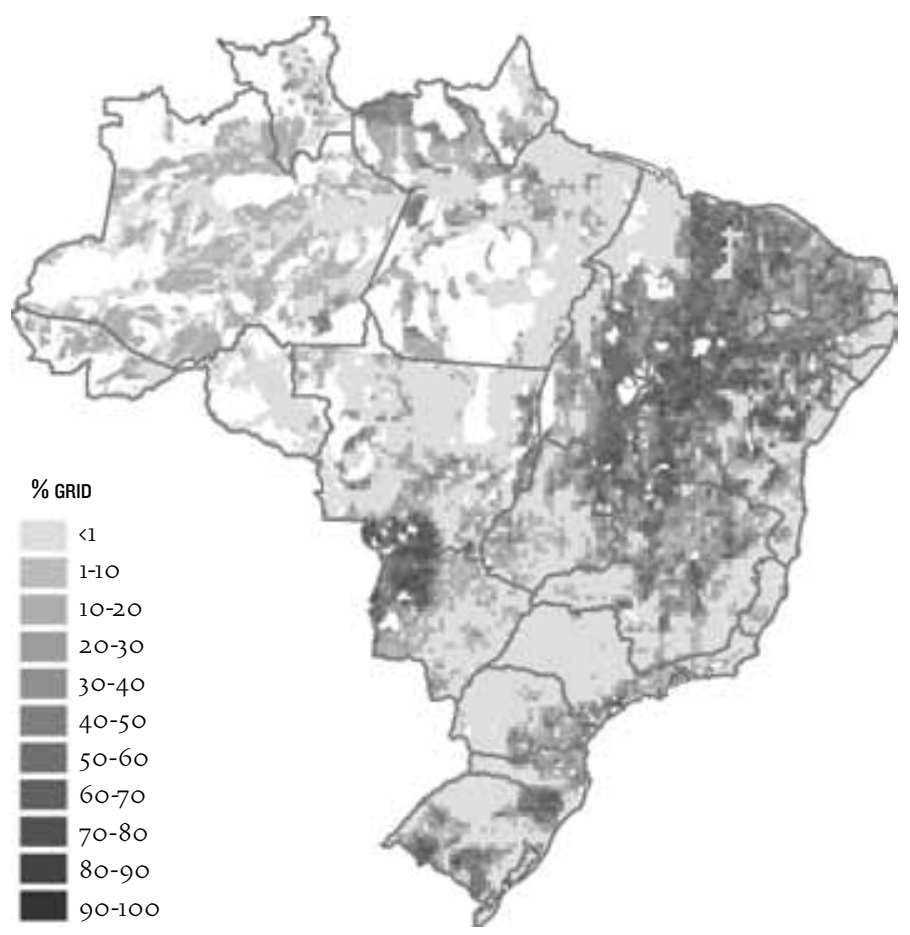

Obs.: O quadriculado (pixels) dos mapas corresponde ao grid de 25 x $25 \mathrm{Km}$ utilizado na modelagem para o cálculo das informações representadas.

A lógica do Código Florestal atual é a da restauração. As áreas de áreas de preservação permanente e de reserva legal são definidas, e quem não cumpre as determinações do código deve restaurá-las por meio do replantio de vegetação natural. Para resolver as situações de não conformidade de RL há também opções de redução de exigências na Amazônia Legal (baseadas em estudos comprobatórios de sua procedência), e a possibilidade de compensação fora da propriedade na mesma microbacia hidrográfica $(\mathrm{MBH})$, ou seja, nas imediações do déficit. Existem outras possibilidades de compensação, mas de aplicação difícil, e por isto pouco efetivas. A ideia de permitir a compensação na $\mathrm{MBH}$ justifica-se pelo princípio ecológico de que a medida compensatória deve ser aplicada perto de onde ocorre o impacto. $\mathrm{Na}$ prática, essa concepção gera restrições enormes para a aplicação do mecanismo. Numa região em que não há conformidade com a RL, quase todas as propriedades possuem passivos; se um proprietário desmatou demais, seus vizinhos devem ter feito o mesmo. Como consequência, não serão encontradas áreas suficientes para compensar 
nas imediações de onde ocorrem os déficits. O mesmo raciocínio vale para o inverso: onde há sobra de VN que pode ser usada para compensação, não haverá déficits, ou seja, demanda suficiente para despertar o interesse pela compensação.

Na proposta do Substitutivo esta lógica foi completamente alterada. A ênfase é na redução de exigências e na ampliação expressiva dos mecanismos de compensação. Este efeito foi alcançado graças à redução de exigências em RL e estendendo a possibilidade de compensação para APP, além de levar os mecanismos de compensação para uma escala de mercado. Restaurar foi trocado por compensar e exigir menos. Como resultado, haveria pouca restauração nas áreas em que ocorrem as não conformidades, e parte importante da enorme área de vegetação natural atualmente não protegida poderia ser inserida na proteção do Código via compensação de RL fora das propriedades, mas longe delas. Há também uma moratória de cinco anos, prorrogável por até mais cinco, para que todos (estados, União, produtores) se adaptem às novas regras. Neste período não haveria novas licenças de desmatamento, mas também não haveria punição àqueles que não cumpriram as exigências da atual legislação no período anterior a $22 / 7 / 2008$.

Caso funcione, o Substitutivo pode ter suas vantagens. Na seção seguinte apresentamos alguns argumentos que apontam o risco de que a própria lógica de gerar conformidade e priorizar a proteção da vegetação natural que ainda está de pé pode não funcionar adequadamente pela forma como os critérios estão definidos no Substitutivo.

\section{AS ARMADILHAS DA DIMINUIC̄ÃO DE EXIGÊNCIAS}

Isenção de quatro Módulos Fiscais do cálculo de RL

Segundo dados do Censo Agropecuário de 2006, $90 \%$ dos imóveis rurais têm menos de quatro módulos fiscais (MF), ocupando $25 \%$ da área total de imóveis. O Substitutivo sugere que o cálculo da área de RL seja feito para a área total do imóvel excluindo 4 módulos fiscais. Ou seja, um imóvel de seis MF contabiliza RL apenas sobre dois MF. Os imóveis rurais menores do que quatro MF ficariam isentos de recomposição da RL faltante, mas o Substitutivo expressamente determina que, mesmo em tais imóveis, "os remanescentes de vegetação nativa existentes em pequenas propriedades ou posses rurais, na data da publicação desta Lei, deverão ser conservados até o percentual previsto" para RL (art. $13, \S 4^{\circ}$ ). Ou seja, nas áreas menores do que quatro MF o que existe de vegetação natural abaixo da exigência legal de RL fica, o que falta, não precisa ser restaurado nem compensado. Aplicando-se tal mecanismo, ocorre uma redução da RL exigida de 236 Mha para 206 Mha. 
O princípio que isenta as propriedades pequenas em relação à exigência da RL é justificável e interessante do ponto de vista do desenvolvimento da agropecuária. Duas questões, entretanto, precisam e não foram adequadamente avaliadas. A primeira diz respeito à efetiva capacidade do Estado em identificar e fiscalizar as áreas remanescente de vegetação nos imóveis isentos de recomposição da RL. Com a aplicação deste mecanismo, os imóveis rurais pequenos deixam de ter uma área mínima fixa de RL, que passa a ser dependente de sua situação específica numa determinada época, portanto diferente para cada propriedade, o que dificulta a fiscalização e o controle. Na prática, uma expressiva quantidade de vegetação natural ficará sem proteção temporária, e poderá ser desmatada sem medo de complicações até o dia em que algum mecanismo de fiscalização (já previsto pelo Substitutivo) consiga determinar sua existência e localização, possibilitando o monitoramento. $\mathrm{O}$ total de $\mathrm{VN}$ envolvido nesta incerteza temporária e dependente da agilidade e eficácia dos órgãos ambientais é de aproximadamente 90 Mha. Segundo o Substitutivo, esta VN estaria protegida (ele determina que não pode haver sua supressão), mas as dificuldades práticas em garantir este princípio são enormes. Isso coloca em dúvida sua viabilidade como mecanismo equilibrado de garantir ao pequeno proprietário a possibilidade da continuidade de acesso às terras que ele já utiliza além daquilo que o Código Florestal permite. Até o dia em que os imóveis rurais do Brasil que têm abaixo de quatro MF (90\% do total) forem vistoriados e sua área de vegetação natural fora de áreas de preservação permanente for definida geograficamente não haverá forma de aplicar o mecanismo. As áreas desmatadas neste período poderiam ficar completamente impunes.

A segunda questão diz respeito à extensão da medida, ou seja, seé razoável ou não fixar em quatro MF a área das propriedades rurais que passariam a ser isentas de recomposição da RL. Uma isenção de 0,25 MF da exigência total de RL já atingiria 50\% do número de imóveis e uma área de aproximadamente $5 \%$ da atual RL exigida. Com uma isenção de um MF teríamos $75 \%$ de imóveis anistiados, algo em torno de $10 \%$ da área da atual de RL exigida. Valores de isenção da exigência de RL nesta faixa de tamanho reduziriam a quantidade de vegetação natural temporariamente desprotegida e não diminuiriam drasticamente a RL total exigida, mantendo ao mesmo tempo o benefício da isenção para a maioria das propriedades pequenas. O equilíbrio entre a viabilização da produção de alimentos pelo segmento mais eficiente no uso produtivo da terra (a agricultura familiar) e a necessidade de preservação da vegetação natural estaria mais garantido.

Estudo recente ${ }^{18}$ demonstra claramente que a agricultura familiar que se enquadra nos critérios do Pronaf ${ }^{19}$ é mais produtiva do que aquela que não se enquadra. O estudo aponta que a participação da
[18] Os valores apresentados foram calculados com base em tabelas contidas em "Quem produz o que no campo:quanto e onde. II: censo agropecuário 2006, resultados: Brasil e regiões". São Paulo/Brasília: Fundação Getúlio Vargas/Instituto Brasileiro de Economia/Confederação da Agricultura e Pecuária do Brasil, 2010 .

[19] O Pronaf (Programa Nacional de Fortalecimento da Agricultura Familiar) oferece diversas formas de crédito (custeio e investimento) para agricultores familiares, ou seja, aqueles que têm pouca terra, fazem a gestão de sua produção tendo como base principal a mão de obra da família, residem na propriedade e se enquadram em critérios específicos de renda bruta anual (baixa renda). O acesso é feito pela DAP (Declaração de Aptidão ao Pronaf) emitida pelo órgão de Extensão Rural local. 
[20]Inúmeros trabalhos científicos provam que a zona ripária (matas ciliares) tem um papel fundamental na preservação da biodiversidade por conta de sua interligação de fragmentos servindo como corredores ecológicos. Além disso, é inegável seu efeito na retenção de sedimentos, evitando impactos extrínsecos da erosão do solo como a poluição da água e o assoreamento de reservatórios. Por fim, em cabeceiras de bacias de drenagem ou em regiões com malha fluvial muito ramificada, ainda exerce papel fundamental na recarga de lençóis freáticos e aquíferos.

[21] Victoria, Hott e Miranda, op. cit. agricultura familiar no Valor Bruto de Produção Agropecuária (VBPA) é relativamente pequeno (23\%), mas este é fruto de apenas $18 \%$ da área total dos estabelecimentos agropecuários. Os 31\% dos estabelecimentos não enquadrados contam com $82 \%$ da área e produzem $76 \%$ do VBPA. O resultado é uma eficiência $40 \%$ maior dos pequenos na utilização do recurso terra. Quem tem pouca terra, claro, precisa utilizá-la de maneira eficiente. Nada mais lógico do que isentar esta parcela dos produtores da exigência de RL, que concorre diretamente com o uso eficiente da terra - que já é pouca -, consumindo parte dela para preservação. Portanto, o erro estaria apenas na dose e na extensão do benefício para áreas maiores, que isenta não só os pequenos produtores, mas também uma pequena parte importante dos maiores.

\section{Nova classe de APPripária}

O Substitutivo prevê uma nova classe de áreas de preservação permanente ripária com $15 \mathrm{~m}$ de largura em cada margem em rios de até $5 \mathrm{~m}$ de largura. A versão atual do Código Florestal prevê APP de $30 \mathrm{~m}$ de largura em cada margem. Analisando apenas a área total de APP ripária afetada por esta medida, sem estimar os prejuízos ecológicos e hidrológicos ${ }^{20}$, calculamos, para o estado de São Paulo, uma redução de $20 \%$ na área total de APP ripária.

A extensão de rios de pequena largura é maior do que de rios mais largos. Isso ocorre porque a rede de drenagem se ramifica nas cabeceiras. A criação de uma nova classe de rios com menos de $5 \mathrm{~m}$ de largura, onde atualmente se aplica em cada margem $30 \mathrm{~m}$ de APP, tem um efeito grande (20\%) na redução do total de APP e potencial mente nos impactos ecológicos negativos.

\section{Exclusão das áreas de topo-de-morro}

A definição de topo-de-morro no Código Florestal, regulamentada pela resolução Conama 303/2002, é de difícil interpretação, mesmo para especialistas no assunto. A primeira tentativa de mapear esta condição de APP abrangendo todo Brasil foi recente $e^{21}$ e resultou numa área de $39 \mathrm{Mha}$ (4,5\% do território nacional continental). Os valores variam muito:nos estados mais planos como AM e AC a porcentagem de topo-de-morro é menor do que 1\%, atingindo valor máximo em SC com $18 \%$ de APP em topo de morro. Não há estimativas nacionais de conformidade de manutenção da vegetação natural na condição de topo-de-morro.

O conceito de APP visa principalmente à conservação dos rios e suas áreas de recarga, além da ocupação com vegetação natural de áreas consideradas prioritárias para conservação do ponto de vista de ecologia da paisagem. A questão de a condição de topo-de-morro se enquadrar neste conceito é muito mais controversa do que no caso das 
áreas ripárias, íngremes ou de altitude elevada. Além disso, o interesse pela ocupação da condição de topo-de-morro com agricultura é muito grande; geralmente são áreas planas e mecanizáveis, o que as difere das outras situações de APP. Acreditamos que o Substitutivo tenha acertado em excluir a condição de topo-de-morro das áreas de APP.

\section{A COMPENSAÇÃO COM CARA DE FAVORECIMENTO DO MERCADO IMOBILIÁRIO}

A compensação de RL, no Código Florestal atual praticamente restrita às microbacias hidrográficas em que os imóveis se inserem, foi ampliada para o Bioma. Numa situação hipotética em que todos os proprietários optassem pela compensação nos seus biomas, apenas na Amazônia haveria estoques de vegetação natural (que excedem as exigências legais, portanto no CF atual não são protegidos) insuficientes para compensar os déficits. No total, restariam 13 Mha de áreas que teriam que ser restauradas, em vez dos atuais $42 \mathrm{Mha}$, todos eles na Amazônia.

Esta abrangência pode dotar o mecanismo da compensação de características do mercado imobiliário, engajando agentes econômicos privados para sua operação em larga escala territorial. Para quem produz e quer legalizar sua situação, compensar fora da propriedade poderá, dependendo da relação oferta e demanda, ser mais barato do que reduzir a área de produção e restaurar a vegetação natural na propriedade onde foi criado o passivo. A maior parte da VN passível deste mercado, ou seja, fazendas em que a quantidade de vegetação natural excede aquela exigida pelo Código, estão em regiões em que a ocupação com agricultura intensiva ainda não está consolidada. A atual opção econômica predominante em tais terras passa pela exploração dos recursos florestais vindos do desmatamento, seguida de seu arrendamento ou produção própria de pecuária de corte extensiva, apresentando, portanto, baixa rentabilidade por área. Tudo indica que é possível a floresta em pé valer mais do que esta opção em um mercado de compensação. $O$ valor da floresta em pé pode ainda ser reforçado pelos novos mecanismos de PSA e REDD ${ }^{22}$, que são complementares à compensação.

Apesar de promissor não só como mercado físico, mas também do ponto de vista das expectativas, ou seja, uma vez desmatado não há como reverter a situação para fins de compensação, a compensação não elimina o vazamento, apenas atenua. Considerando a mais ampla possível aplicação do mecanismo de compensação, a vegetação natural não protegida diminui de 103 Mha para 71 Mha (Tabela 2). O efeito em alguns biomas é maior, como no caso da Mata-Atlântica (redução de 10 Mha para 1 Mha), e em outros, menor, como no Cerrado (redução de 43 Mha para 37 Mha).
[22] PSA (Pagamento por Serviços Ambientais); REDD (Redução de Emissões por Desmatamento e Degradação). 
Uma forma de regular este mercado, e complementar as ações de redução do vazamento, é a criação de unidades de conservação ou terras indígenas em áreas de interesse prioritário e de atuação potencial muito grande do mercado de compensação. Outra alternativa é a definição de polígonos de compensação que não sejam o bioma, a fim de direcionar geograficamente as áreas a serem protegidas. Um exemplo seria a definição de polígonos de compensação coincidentes com as áreas de ampliação da fronteira agrícola. No caso da dinâmica predominante no polígono ser a expansão da fronteira agrícola pelo desmatamento, e a regra de compensação se aplicar apenas a este polígono, não permitindo assim a compensação em áreas distantes (onde não haveria pressão de desmatamento e a vegetação natural já estaria protegida por isto), haveria competição entre a compensação e a conversão. Provavelmente, a conversão iria ocorrer apenas nas terras melhores, que seriam depois utilizadas com alta produtividade. As áreas de baixa aptidão agrícola valeriam mais se remuneradas pelo mercado de compensação.A ampliação exagerada dos polígonos de compensação, como é claramente o caso de considerar todo o bioma, implica o risco de proteger a custos baixíssimos apenas a vegetação natural de regiões tão remotas e tão desprovidas de aptidão para agricultura que já estariam em grande parte protegidas só por isto. Neste caso não haveria um mercado atraente como opção para as áreas em que a pressão de desmatamento efetivamente existe, decorrente da baixa remuneração influenciada pelas áreas remotas.

O Substitutivo permite a compensação de RL em APP na propriedade. A área de APP preservada pode ser descontada da área necessária para satisfazer o critério de RL. O Substitutivo condiciona tal benefício a três requisitos (art. 15): "i) não implique a conversão de novas áreas para uso alternativo do solo, ii) a área a ser computada esteja conservada ou em processo de recuperação, e iii) o proprietário ou possuidor tenha requerido inclusão do imóvel no cadastro ambiental". O efeito potencial é uma redução do déficit de RL de 42 Mha para 35 Mha (Tabela 2). Duas observações, no entanto, precisam ser adequadamente avaliadas. A primeira, novamente, refere-se ao risco de o poder público não dispor de meios eficazes para controlar a contabilização das APP computadas no cálculo da RL, deixando a área de RL de cada imóvel variável e, portanto, difícil de fiscalizar. A segunda compara esta iniciativa com a compensação de RL no bioma fora da propriedade, que, além de gerar conformidade, inclui um componente de proteção. Áreas não protegidas pelo Código Florestal passariam a esta condição. Na compensação de RL em APP isso não se verifica, pois estas já possuem proteção específica na legislação atual. Assim, o único mecanismo atuante desta medida é o da redução de exigência. 
Alterações nesta regra do Substitutivo, permitindo a compensação de RL apenas em APP totalmente restaurada, poderia fortalecer o componente de restauração. Na maior parte das áreas onde há passivos de vegetação natural em APP o mesmo ocorre com a RL.A restauração da APP para permitir que ela compense RL teria, neste regra, o estímulo de abater a mesma quantidade de área da dívida de RL. Cada hectare de APP restaurada abateria também um hectare da exigência de RL.A restauração neste caso, por se tratar de APP (já excluindo topo-de-morro), ocorreria em áreas consideradas prioritárias do ponto de vista ecológico, permeando, como os rios, toda a paisagem.

Por fim, cabe destacar que a redução de exigências de restauração pode assumir proporções ainda maiores no caso da APP. Segundo o Substitutivo, em regiões de agricultura consolidada, justamente aquelas em que há os maiores déficits de APP e a maior demanda por água de outros setores - uma dos principais motivos para se manter as matas ciliares - , a anistia por restauração das APP pode ser completa.

\section{O RISCO dE DESEQUILÍBRIO ENTRE REDUÇÃO dE EXIGÊNCIAS E COMPENSAÇÃO}

A aplicação do conjunto do Substitutivo e a atuação simultânea de seus principais mecanismos de redução de exigências e compensação (Tabela 2) mostram um claro risco de desequilíbrio entre seus componentes, comprometendo sua lógica principal. Os mecanismos de redução de exigência ficaram desproporcionais em relação aos de compensação (que protegem a vegetação natural de áreas privadas não protegidas pela aplicação do Código Florestal) e à necessidade de restauração (que pode ser praticamente excluída do novo Código).

Existem algumas formas de ajustar em parte os mecanismos, permitindo, assim, que o novo Código funcione conforme sua lógica de equilíbrio entre possibilidade de conformidade, preservação da vegetação natural que ainda está em pé e redução (mas não extinção) da restauração. Elas podem ser viabilizadas por alterações pontuais nas próprias regras sugeridas no Substitutivo:

- Garantir eficácia da regra que condiciona a compensação de RL em APP apenas quando a totalidade da APP estiver restaurada ou preservada. Isso resgata o interesse pela restauração das APP.

- A não redução de exigência de APP ripária, por declividade ou altitude em caso algum, preserva o viés de restauração nas áreas de maior relevância ecológica.

- A alteração de quatro MF para propriedades anistiadas para um valor entre 0,25 e um MF mantém a exigência de RL elevada, preservando o mecanismo de compensação em escala suficiente para atrair o mercado. 
- A compensação não tem capacidade de evitar o vazamento, mas a complementação desta ação com a criação de UC/TI (ou outras formas de preservação públicas) combinadas com os promissores PSA REDD podem aos poucos incluir os 71 Mha que ainda estariam sem proteção, mesmo com a aplicação do Código Florestal.

O substitutivo escolheu adequadamente os mecanismos para atingir o objetivo de tornar o Código mais efetivo e eficiente. No entanto, em alguns pontos, errou nas doses, incidindo no grande risco de que a restauração e a compensação fiquem quase anuladas, pela redução excessiva de exigências.

\section{MORATÓRIA E PERÍODO DE ADAPTAÇÃo}

Certamente, um período de adaptação precisa ser definido para que os atores envolvidos, que não são poucos, se adaptem às novas regras. O período de cinco mais cinco anos para que estados, União, comitês, órgãos estaduais, produtores rurais e outros tomem as medidas necessárias (que incluem estudos complexos e o fortalecimento ou criação de diversas instituições locais como os Comitês de Bacias) pode ser considerado pouco tempo, mesmo sob o ponto de vista de exequibilidade. Apenas como exemplo, os estudos para que os estados definam diversas regras de Regularização Ambiental incluem a discriminação e georreferenciamento de todas as propriedades rurais. Haja otimismo para acreditar que isto seja viável em cinco anos.

Noentanto, existem outras razões para pensarem ampliaro período de moratória. A principal delas é o fato de não precisarmos da abertura de novas terras num prazo de cinco anos, pelo menos do ponto de vista teórico, para sustentaro desenvolvimento da agropecuária. O prazo de cinco anos é muito curto para que os setores que atualmente se beneficiam da abertura de novas terras e dos desmatamentos promovam mudanças estruturais. Um prazo maior sem licenças para conversão de áreas pode acelerar, ou disparar, um modelo de desenvolvimento em que a viabilidade é gerada sem degradação. Antes de quinze ou vinte anos certamente não serão necessárias novas áreas para ampliar o agronegócio. Vamos primeiro pensar em usar bem o que já abrimos para apenas depois, com muito cuidado, avaliar se realmente há necessidade de conversão de novas áreas. As evidências que apresentamos aqui indicam que se esta necessidade realmente vier a existir, ela só ocorrerá daqui a muito tempo.

Existem algumas exceções, que visam a interesses locais. No Mapito-BA, talvez a última fronteira de expansão de lavouras do Brasil, ainda há perto de 7 a 10 Mha de chapadões de terras férteis cobertos 
com cerrado (Tabela 2, Figura 2). Caso estas áreas sejam convertidas em soja, milho ou cana, certamente haverá benefícios sociais e econômicos importantes e que devem ser priorizados. Caso a conversão de uso seja para pecuária extensiva de baixa produtividade, o cerrado será desmatado, mas sem a geração de benefícios coletivos justificáveis. O importante é evitar que a vontade de ocupar este reduzido estoque de terras férteis, compreensível na lógica econômica e na realidade local, gere processos que farão com que outros 30 Mha de vegetação natural em terras de baixa aptidão para uso agrícola sejam sacrificados.

\section{POR QUE NÃO UM POUCO DE CONTROLE SOCIAL?}

Apesar dos enormes avanços tecnológicos das últimas décadas na obtenção, no acesso, na qualidade e na capacidade de interpretação de imagens de satélite (sensoriamento remoto) e no seu relacionamento com objetos cartográficos e bases de dados (geoprocessamento), o tratamento do Código Florestal neste contexto ainda é praticamente nulo. Nas cidades, as técnicas de sensoriamento remoto e geoprocessamento já são largamente utilizadas sobre a base de seu domínio privado (terrenos, casas e demais edificações) para aplicações que vão desde a localização das piscinas na orientação de vendedores de produtos para sua limpeza, até a atualização de cadastros de impostos municipais nos quais a área edificada é confrontada com informações cadastrais.

Alimitação de aplicação no caso do Código justifica-se pela inexistência de uma base de dados cartográfica de propriedade da terra rural. Não sendo possível delimitar as fazendas, não é possível monitorar remotamente quem está cumprindo ou deixa de cumprir o Código, anulando quase que completamente a utilidade das poderosas ferramentas tecnológicas que revolucionaram, e continuam revolucionado, tantas áreas. Novamente, a inexistência de uma informação cartográfica pública em que os limites das propriedades rurais se encontram definidos não tem como causa restrições tecnológicas. Desse ponto de vista, é fácil imaginar ferramentas ágeis que poderiam gerar em pouco tempo, e com custos muito baixos, uma visão abrangente, mesmo que pouco precisa, da nossa malha fundiária. Por exemplo, um aplicativo de internet em que os proprietários identificassem, de forma declaratória, suas propriedades de terra tendo como suporte ferramentas de edição, imagens de satélite e informações de elementos cartográficos comuns (nome dos rios, das estradas, limites municipais...) já está mais para a realidade do que para a ficção.

Para a análise do Código Florestal, e outros temas de interesse ambiental, esta precisão seria suficiente. A demarcação topográfica 
precisa e com marcos físicos no terreno, para fins de confirmação dominial, pode ser feita posteriormente, com a calma e o rigor de precisão necessários para esta finalidade. Nas questões ambientais, como a identificação de desmatamentos ou conformidade com Código, bem como na demarcação de regiões de dominialidade questionável (terras devolutas representadas por ausência de declaração, ou grilagem representada pela sobreposição de declarações) poderiam ser facilmente identificadas. Nessas aplicações a informação se torna poderosa, e ao mesmo tempo essencial, e pode melhor orientar a aplicação dos poucos recursos disponíveis para fiscalização local necessária para a confirmação das ocorrências e execução das providências.

Caso um mapa atualizado da malha fundiária existisse, também com poucos recursos, as universidades, os institutos de pesquisa, a sociedade e o próprio governo poderiam gerar indicadores gerais de conformidade com o Código Florestal de forma continuada, permitindo assim seu monitoramento. Isto já ocorre, desde 2002, com o desmatamento na Amazônia, em que diversos grupos assumiram o papel de monitorar a degradação e foram, com isso, capazes de interferir de forma eficaz e ativa no seu retrocesso. O elemento que permitiu esse tipo de ação foi a divulgação pública pelo Ministério do Meio Ambiente dos mapas das áreas desmatadas, informação que já existia anteriormente, mas com acesso restrito a uma base tabular. A divulgação certamente contribuiu para as importantes reduções de desmatamento observadas a partir de 2004.

A falta de informação abrangente, pública, atualizada e acessível de nossa malha fundiária não se justifica por limitações tecnológicas ou orçamentárias, mas certamente tem forte respaldo político. $\mathrm{O}$ Substitutivo é atento a esta questão quando inclui a necessidade do georreferenciamento e a discriminação das propriedades nos estudos necessários para que os estados e a União se adaptem às novas regras durante o período de moratória. O importante na regulamentação de como isto deverá ser feito é a desvinculação com a precisão e o rigor cartográfico necessários às escrituras. Se for para fazer dessa forma, com certeza cinco anos não serão suficientes para que a informação seja gerada. Para os estudos necessários e seu monitoramento é imprescindível ter uma ferramenta ágil, com princípio declaratório, e que possa ser atualizada continuamente sempre que a dominialidade de uma gleba for alterada. Atualização, agilidade e publicidade são as palavras que podem fazer o processo funcionar; já temos um exemplo, no controle social do desmatamento na Amazônia. Não há razões para o mesmo princípio de monitoramento e possibilidade de ampla fiscalização não funcionar no caso do Código Florestal, que, no final das contas, é responsável por área de proteção de vegetação natural maior do que as florestas da Amazônia. 
O destino dado pelo Homem às terras, preservando ou desmatando as florestas, intensificando ou não seu uso agrícola, tem impactos diferentes em termos ecológicos (qualidade da água, do ar, dos solos; preservação de flora e fauna), econômicos (geração de riqueza, distribuição de renda) e fenômenos sociais (migração, emprego). Nesse contexto, o Código Florestal é um instrumento legal que pretende, pela regulamentação do uso do solo, minimizar os impactos negativos causados pela substituição da vegetação natural por outros usos, predominantemente a agropecuária. A vN é considerada no Código como um bem de interesse comum; portanto, justifica-se sua regulamentação pública mesmo nas propriedades privadas ou posses rurais.

A elaboração e revisão do Código ao longo dos anos aumentaram as restrições das terras (de jure), mas estas foram ineficazes (de facto), constituindo atualmente uma realidade onde o Código vigente dificilmente seria aprovado se de fato aplicado, dado o balanço de poder entre interesses da sociedade.A diferença entre a lei eo seu cumprimento tornou-se hoje motivo de reversão das negociações políticas, em que os argumentos para menores restrições são valorizados, visando a mudanças no Código Florestal ${ }^{23}$.

O fato de o atual debate sobre a revisão do Código corresponder a esse padrão não significa que o processo de sua constituição tenha resultado em uma lei desprovida de justificativas ecológicas. Pelo contrário, o CF garante direitos difusos de toda a sociedade brasileira. Os resultados potenciais do Código são necessários à sociedade. Vários estudos demonstram a importância ecológica das florestas e do próprio CF como principal ferramenta de conservação da flora, da fauna, da produção de água e regulação climática ${ }^{24}$, recursos indispensáveis, inclusive, à atividade agropecuária.

No entanto, o fato de haver justificativas ecológicas e garantia de direitos difusos não extingue a necessidade do debate sobre a sua revisão. Em primeiro lugar, porque a criação do CF e o passivo gerado ao longo dos anos tendem a confirmar o interesse pelo atual debate para sua revisão, com tendência de flexibilizações das regras ${ }^{25}$. Em segundo, o passivo acumulado ao longo dos anos é com certeza grande o suficiente para gerar dúvidas sobre a capacidade econômica de sua restauração, os custos e os benefícios implicados. Em terceiro, a ampla aplicação do CF ainda permite o desmatamento de 103 Mha de vegetação natural.Por último, e talvez o tema mais negligenciado no debate, a necessidade de responder por que o Código Florestal não produziu os efeitos desejados, e como alterações, adaptações, ou regulamentações podem chegar a tal resultado no futuro, mesmo que o efeito desejado seja outro (menos restrito).

\footnotetext{
[23] Cf. Alston, L. G. e Muller, B. "Legal reserve requirements in Brazilian forests: path dependent evolution of de facto legislation". Revista Economia, Brasília, vol. 8, no 4, 2008, pp. 25-53.
}

[24] Cf. Sparovek e outros, op. cit.; Malhi, Y. e outros. "Climate change, deforestation, and the fate of the Amazon". Science, $\mathrm{n}^{\circ}$ 319, 2007, pp. 169-72.

[25] Cf. Alston e outros, op. cit. 
[26] Cf. Lambin, E. F., Rounsevell, M. D. A. e Geist, H. J. “Are agricultural land-use models able to predict changes in land-use intensity?". Agriculture, Ecosystems and Environment, $\mathrm{n}^{\circ} 82,2000$, pp.321-31.

Recebido para publicação em 2 de setembro de 2010 .

\section{NOVOS ESTUDOS}

CEBRAP

89, março 2011

pp. 111-135
A compreensão de onde, quando e porquê de a intensificação e as mudanças de uso do solo ocorrerem e como o Código interfere nestas mudanças pode auxiliar uma revisão que produza os efeitos desejados (eficazes) e que gere uma relação equilibrada entre custos e benefícios de implementação (eficiência). Para alcançar tal propósito, são necessárias pesquisas que se tenham base em modelos de uso do solo. Esses modelos são representações do atual uso do solo e de mudanças ocorridas no passado, ou que ocorrerão no futuro. São explicitamente geográficos, ou seja, geram dados espacializados que auxiliam na compreensão dos processos e determinam seus resultados quantitativos ${ }^{26}$.

É nesse contexto que se inserem os dados apresentados nesta análise, os quais podem contribuir no atual debate sobre a revisão do Código Florestal, proporcionando respostas basicamente a dois grandes temas: 1) conhecer a realidade para racionalizar o debate, 2) indicar subsídios para que o Código seja mais eficaz e efetivo.

GERD SPAROVEK é professor da Escola Superior de Agricultura “Luiz de Queiroz" (Esalq) da Universidade de São Paulo.

ALBERTO BARRETTO é doutorando da Esalq-USP e produtor rural.

ISRAEL KLUG é agrônomo.

LEONARDO PAPP é mestre em Direito Ambiental pela Universidade Federal de Santa Catarina. JANE LINO é mestranda da Esalq-USP. 